\title{
Molsidomine for the prevention of vasospasm-related delayed ischemic neurological deficits and delayed brain infarction and the improvement of clinical outcome after subarachnoid hemorrhage: a single-center clinical observational study
}

\author{
Angelika Ehlert, MD, ${ }^{1}$ Christoph Schmidt, MD, ${ }^{2}$ Johannes Wölfer, MD, ${ }^{3}$ Gerd Manthei, MD, ${ }^{1}$ \\ Andreas H. Jacobs, MD, ${ }^{4}$ Roland Brüning, MD, ${ }^{5}$ Walter Heindel, MD, ${ }^{6} \mathrm{E}$. Bernd Ringelstein, MD, ${ }^{7}$ \\ Walter Stummer, MD, ${ }^{3}$ Ryszard M. Pluta, MD, ${ }^{8}$ and Volker Hesselmann, MD ${ }^{6,9}$

\begin{abstract}
${ }^{1}$ Department of Neurosurgery, Asklepios Hospital St. Georg, Hamburg; Departments of ${ }^{2}$ Anästhesiology, Intensive Care and Pain Medicine, ${ }^{3}$ Neurosurgery, ${ }^{6}$ Radiology, and ${ }^{7}$ Neurology, University Hospital Münster; ${ }^{4}$ European Institute of Molecular Imaging, Münster; ${ }^{5}$ Department of Radiology, Asklepios Hospital Barmbek, Hamburg; ${ }^{9}$ Asklepios Hospital Hamburg North, Hamburg, Germany; and ${ }^{8}$ Surgical Neurology Branch, National Institute of Neurological Disorders and Stroke, National Institutes of Health,
\end{abstract} \\ Bethesda, Maryland
}

OBJECTIVE Delayed ischemic neurological deficits (DINDs) and cerebral vasospasm (CVS) are responsible for a poor outcome in patients with aneurysmal subarachnoid hemorrhage (SAH), most likely because of a decreased availability of nitric oxide (NO) in the cerebral microcirculation. In this study, the authors examined the effects of treatment with the NO donor molsidomine with regard to decreasing the incidence of spasm-related delayed brain infarctions and improving clinical outcome in patients with SAH.

METHODS Seventy-four patients with spontaneous aneurysmal SAH were included in this post hoc analysis. Twentynine patients with SAH and proven CVS received molsidomine in addition to oral or intravenous nimodipine. Control groups consisted of $25 \mathrm{SAH}$ patients with proven vasospasm and $20 \mathrm{SAH}$ patients without. These patients received nimodipine therapy alone. Cranial computed tomography (CCT) before and after treatment was analyzed for CVS-related infarcts. A modified National Institutes of Health Stroke Scale (mNIHSS) and the modified Rankin Scale (mRS) were used to assess outcomes at a 3-month clinical follow-up.

RESULTS Four of the 29 (13.8\%) patients receiving molsidomine plus nimodipine and 22 of the 45 (48\%) patients receiving nimodipine therapy alone developed vasospasm-associated brain infarcts $(p<0.01)$. Follow-up revealed a median mNIHSS score of 3.0 and a median mRS score of 2.5 in the molsidomine group compared with scores of 11.5 and 5.0 , respectively, in the nimodipine group with CVS $(p<0.001)$. One patient in the molsidomine treatment group died, and 12 patients in the standard care group died $(p<0.01)$.

CONCLUSIONS In this post hoc analysis, patients with CVS who were treated with intravenous molsidomine had a significant improvement in clinical outcome and less cerebral infarction. Molsidomine offers a promising therapeutic option in patients with severe SAH and CVS and should be assessed in a prospective study.

http://thejns.org/doi/abs/10.3171/2014.12.JNS13846

KEY WORDS subarachnoid hemorrhage; molsidomine; CVS; DIND; vasospasm; NO; vascular disorders

ABBREVIATIONS ACA = anterior cerebral artery; $\mathrm{BA}=$ basilar artery; $\mathrm{BP}=$ blood pressure; $\mathrm{CBF}=$ cerebral blood flow; $\mathrm{CCT}=\mathrm{cranial}$ computed tomography; $\mathrm{CVS}=$ cerebral vasospasm; DIND = delayed ischemic neurological deficit; DSA = digital subtraction angiography; GCS = Glasgow Coma Scale; HES = hydroxyethyl starch; HH = Hunt and Hess; ICA = internal carotid artery; ICP = intracranial pressure; MAP = mean arterial blood pressure; MCA = middle cerebral artery; mNIHSS = modified National Institutes of Health Stroke Scale; mRS = modified Rankin Scale; $M T G=$ molsidomine treatment group; $\mathrm{NO}=$ nitric oxide; $\mathrm{SAH}=$ subarachnoid hemorrhage; STG = standard therapy group; TCD = transcranial Doppler; $V A=$ vertebral artery.

SUBMITTED May 5, 2013. ACCEPTED December 29, 2014.

INCLUDE WHEN CITING Published online July 10, 2015; DOI: 10.3171/2014.12.JNS13846.

DISCLOSURES The authors report no conflict of interest concerning the materials or methods used in this study or the findings specified in this paper. 
$\mathrm{U}$ P to $50 \%$ of patients suffering from subarachnoid hemorrhage (SAH) develop delayed cerebral infarction and persistent neurological deficits. In up to $25 \%$ of cases, delayed strokes are responsible for severe disabilities,, 916 and approximately $75 \%$ of patients with SAH experience persistent cognitive or mental deficits. Depending on the selection of patients, only a minority of survivors recover to a normal quality of life or return to work $(6 \%-60 \%) .{ }^{1,24}$

Since the implementation of nimodipine in 1983, no new therapeutic approach for vasospasm-associated delayed ischemic neurological deficits (DINDs) after SAH has achieved general acceptance. Only orally administered nimodipine has been shown to decrease the risk of DIND or poor clinical outcome., ${ }^{2,9,16}$ Despite nimodipine treatment, vasospasm-associated infarcts occur in $20 \%-$ $50 \%$ of patients with SAH, DINDs in $27 \%-37 \%$ of patients, and severe morbidity in $30 \%-40 \%$ of patients. , $^{9,13,17}$ A favorable outcome has been reported in less than $10 \%$ of patients with DIND, and the majority of those patients (62\%) have a poor outcome (severe disability, coma, death). ${ }^{17}$

Arteriographic vasospasm is detected in approximately $60 \%-70 \%$ of patients after SAH, but not all of them develop DINDs, possibly because of a sufficient collateral blood supply. ${ }^{916}$ On the other hand, cerebral vasospasm (CVS), as detected by transcranial Doppler (TCD) ultrasonography or arteriography, is not present in every patient with DINDs. In these cases, DINDs have been attributed to decreased blood flow through the microcirculation due to a locally reduced availability of nitric oxide (NO). ${ }^{18,19}$ Thus, detectable CVS in the macrocirculation may facilitate the development of DINDs but is not necessarily its main cause. These findings suggest that the impact of cerebral microcirculation on the development of DINDs and poor outcome has been underestimated..$^{11,18,19}$

Recently, this concept was further supported by results of the CONSCIOUS 1-3 trials, which treated CVS patients with endothelin receptor antagonists, and a newly published randomized trial investigating the therapeutic effect of cilostazol, an inhibitor of phosphodiesterase $3 .^{26}$ TCD ultrasonography-detectable vasospasm was significantly reduced, but the rate of DINDs and related infarcts showed only a statistical trend toward improvement, and the clinical outcome was not altered, ${ }^{1,15,21}$ possibly because clazosentan acted only on the large conductive cerebral arteries.

For years, many treatments of DINDs and CVS after SAH have been tried, including compounds with improved NO delivery. Several of them showed beneficial effects on CVS, DIND, or clinical outcome., ${ }^{9,16,19,20}$ Unfortunately, some NO-delivering drugs and their administration routes have been associated with side effects such as systemic hypotension or cyanide toxicity. ${ }^{7}$ An alternative NO donor with more favorable pharmacodynamic and pharmacokinetic profiles and less toxicity is molsidomine, a standard treatment for heart failure and coronary heart disease..$^{25,27}$ Thus, in this study, we used intravenously administered molsidomine as a rescue therapy in SAH patients with established CVS and observed its effect on the occurrence of DINDs, vasospasm-related infarcts, and clinical outcome.

\section{Methods Patients}

Seventy-four consecutive patients with spontaneous aneurysmal SAH (age 16-86 years; mean 54.5 years, SD 14.7) had been admitted to the intensive care unit of the University Hospital Münster, Germany, between January 2008 and September 2009. All patients were treated with nimodipine. Twenty-nine consenting patients with CVS received molsidomine in addition to the standard nimodipine therapy when clinical deterioration was obvious (molsidomine treatment group [MTG]). The control group receiving standard nimodipine therapy consisted of 45 patients (standard therapy group [STG]). In this STG, 25 patients had CVS but refused molsidomine therapy (STG-CVS). Twenty patients presented without CVS (STG-noCVS; Fig. 1). Epidemiological characteristics of the patient population are presented in Table 1. The locations of the aneurysms are presented in Table 2.

To avoid the inclusion of death events due to reasons other than CVS, we excluded from evaluation 9 patients who died within the first 6 days after SAH because of generalized brain edema, severe hypoxia, massive rebleeding, or a relevant mass shift due to parenchymal hematoma or causes directly related to procedures.

Within 24 hours of admission, the aneurysms were treated by coil embolization and/or clipping. Patients treated by coiling received aspirin (100 $\mathrm{mg} /$ day). In the MTG, 20 patients were treated with coil embolization, 6 patients were treated with clipping, and 3 patients received both clipping and coiling. In the STG, 31 patients were treated with coil embolization, 12 patients with clipping, 1 patient with coiling and clipping, and 1 patient was not treated at all.

Thirty-six patients received the standard therapy with nimodipine 6 tablets $\times 60 \mathrm{mg} /$ day orally or via feeding tube. Thirty-eight patients with deteriorated intestinal absorption received intravenous nimodipine $1-2 \mathrm{mg} / \mathrm{hr}$ in the first days after SAH. TCD ultrasonography was performed daily and included mean velocity measurements of the internal carotid artery (ICA), the middle cerebral artery (MCA), the anterior cerebral artery (ACA), the vertebral arteries (VAs), and the basilar artery (BA). CVS was diagnosed using 3 methods: 1) TCD ultrasonography, if the mean flow velocity in the ACA and the MCA was above $140 \mathrm{~cm} / \mathrm{sec}$ or if it was $>120 \mathrm{~cm} / \mathrm{sec}$ in the BA and VA, with a Lindegaard index $>3 ; 2$ ) arteriography, if narrowing $>50 \%$ of the vessel diameter, as compared with initial values, was detected and DIND was argued; or 3) the appearance of clinical symptoms within Day $3-14$, such as loss of consciousness or newly developed focal neurological deficits, including dysphasia, hemiparesis, psychotic episodes, a decrease in the Glasgow Coma Scale (GCS) score by at least 1 (for example, GCS Score 4 decreasing to GCS Score 3), or a median GCS score below 3 that was not attributable to other causes if it occurred within 3-14 days after SAH.

All patients received standard intensive care unit (ICU) medical care that maintained normovolemia and normothermia; all laboratory parameters and blood gases were kept at normal ranges; intracranial pressure (ICP), elec- 


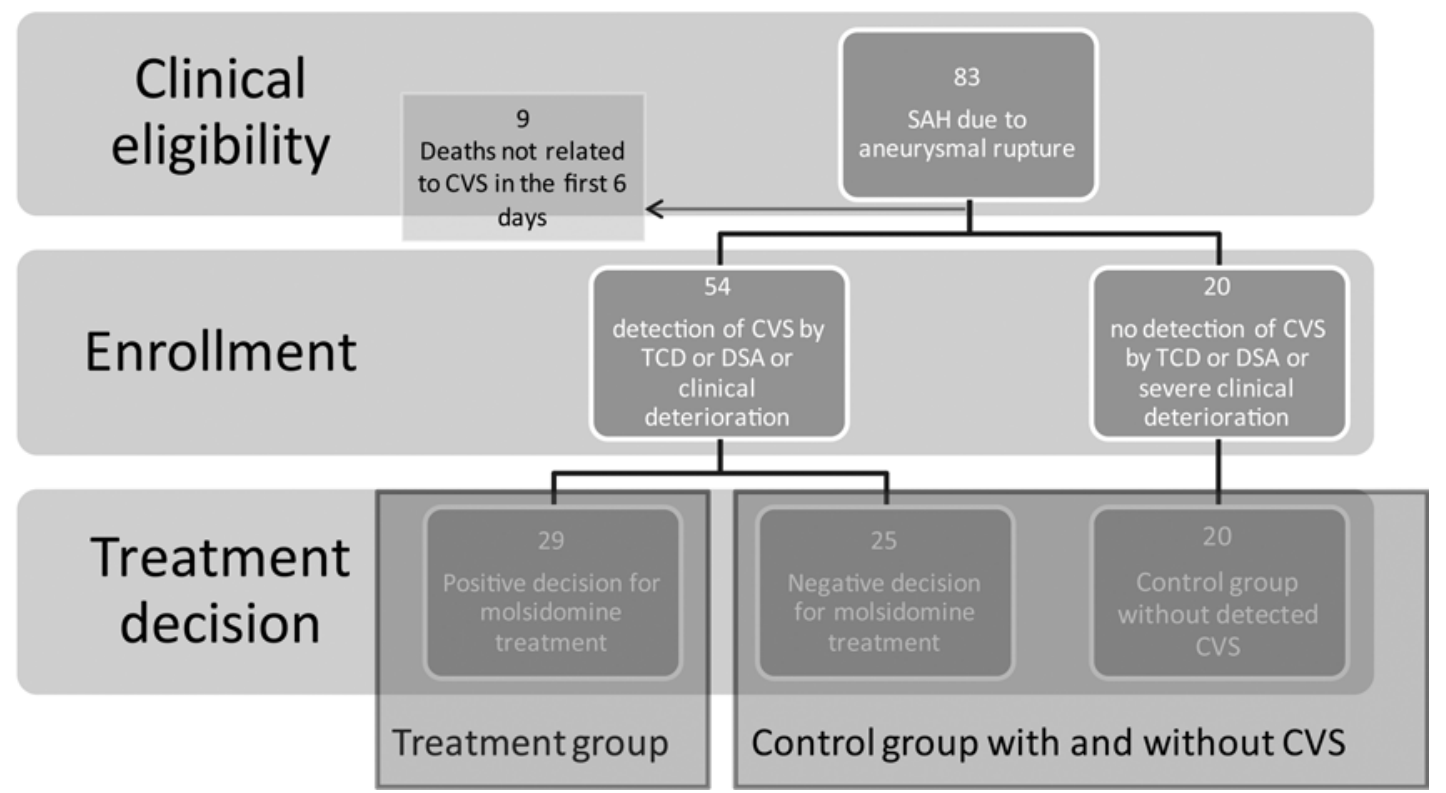

FIG. 1. Flowchart of patient enrollment into the different treatment groups.

trocardiography (ECG), and arterial blood pressure (BP) values were monitored continuously and per hour. The GCS score was assessed hourly. The hematocrit was kept at $\pm 30 \%$. The ICP was maintained at $<20 \mathrm{~mm} \mathrm{Hg}$ either medically or by CSF drainage. Blood transfusions were given at a hemoglobin level $<8 \mathrm{mg} / \mathrm{dl}$; a ventriculostomy was performed before coiling if necessary or in cases of posthemorrhagic hydrocephalus. The initial target mean arterial blood pressure (MAP) was 70-90 mm Hg: the target MAP was kept to $>90 \mathrm{~mm} \mathrm{Hg}$ for the STG-CVS and $>65-70 \mathrm{~mm} \mathrm{Hg}$ for the MTG.

Molsidomine was administered via a darkened continuous intravenous infusion as soon as CVS was confirmed and consent was obtained; the starting dose was 20-40 $\mathrm{mg} / 24$ hours. This dose was carefully titrated according to MAP (goal: > 65-70 $\mathrm{mm} \mathrm{Hg}$ ) to a target rate of 3.5-10 $\mathrm{mg} / \mathrm{hr}$ depending on MAP and the need for vasopressors (goal: $<0.2 \mu \mathrm{g} / \mathrm{kg} / \mathrm{min}$ ); otherwise, we reduced the dose gradually, keeping in mind the possibility of a rebound and the short half-life of molsidomine ( 2 hours). After resolution of the CVS, the molsidomine treatment dose was carefully reduced under TCD control; then molsidomine was switched to the oral application $(4 \times 8 \mathrm{mg}$, slow release molsidomine). The molsidomine therapy lasted as long as the treatment with nimodipine, i.e. on average 16 days (range: 14-28 days).

In the 29 patients in the MTG and in the 25 patients in the STG-CVS, vasospasm was confirmed by TCD and clinical deterioration using the Vergouwen multimodal disciplinary approach. ${ }^{33}$ At the time of detected CVS, all patients underwent a diagnostic arteriography followed by local, intraarterial nimodipine infusions over 20 minutes (with $2 \mathrm{mg}$ nimodipine $/ 50 \mathrm{ml} \mathrm{NaCl} 0.9 \%$ ) and rheological support with 6\% hydroxyethyl starch (HES). No triple$\mathrm{H}$ therapy was administered in order to avoid excessive vasopressor doses and extreme blood pressure levels, as there is a body of evidence suggesting a worse outcome at high blood pressure levels. ${ }^{14}$ Moreover, high doses of noradrenalin have been reported to cause an increased risk of vasospasm in a dose-dependent manner. ${ }^{5}$

As a follow-up, we analyzed the effects of molsidomine-treated patients and retrospectively compared the outcome parameters of the STG with those of the MTG 3 months after disease onset (significance level $<0.05$ ). Additionally, we compared the subgroups STG-CVS and STG-noCVS with the MTG (significance level $p<0.016$, Bonferroni corrected). Further, we subdivided Hunt and Hess (HH) grades into the subgroups (I) Grades I-II and (II) Grades III-V to assess clinical outcomes at 3 months using the modified National Institutes of Health Stroke Scale (mNIHSS) and modified Rankin Scale (mRS).

Molsidomine was supplied by Sanofi Inc. and Therabel Pharmaceuticals Ltd. (Belgium) in ampoules of $2 \mathrm{mg} / \mathrm{ml}$ and $20 \mathrm{mg} / 10 \mathrm{ml}$, respectively. Orally administered molsidomine was supplied by Sanofi Inc. ( $8 \mathrm{mg} / \mathrm{dose})$.

The following were treatment criteria for the administration of molsidomine: age $>18$ years, spontaneous SAH, presence of CVS, clinical stage of HH Grade I-V with clinical worsening, and written informed consent by the patients or their relatives. No patient was offered molsidomine treatment if there were no signs of CVS or if they suffered from sustained hypotension and low MAP output below $65 \mathrm{~mm} \mathrm{Hg}$, were pregnant, or had generalized cerebral edema with a high risk of cerebral herniation. Patient enrollment and the inclusion and exclusion process are presented in Fig. 1.

Cranial computed tomography (CCT) and digital subtraction angiography (DSA) images were independently analyzed by 2 blinded, experienced neuroradiologists (V.H., T.N.) for signs of infarction and vasospasm. CVSrelated infarcts were diagnosed based on the presence of hypodense lesions occurring 72 hours or more after therapeutic intervention or operation as compared with the 24-hour control CCT scan. To determine the clinical 
TABLE 1. Patient characteristics: epidemiological data, medical history, and drug history

\begin{tabular}{|c|c|c|c|c|}
\hline Parameter & MTG & STG-CVS & STG & $\mathrm{p}$ Value \\
\hline No. $(\%)$ & $29(39)$ & $25(34)$ & $20(27)$ & \\
\hline Age in yrs (range) & $49(26-77)$ & $52(16-76)$ & $64(42-86)$ & 0.002 \\
\hline Mean HH grade (range) & $3(1-5)$ & $4(1-5)$ & $4(1-5)$ & NS \\
\hline Sex female $(\%)$ & $21(72)$ & $15(60)$ & $14(70)$ & NS \\
\hline Sex male (\%) & $8(27.6)$ & $10(40)$ & $6(30)$ & \\
\hline Fisher scale score (range) & $4(1-4)$ & $4(2-4)$ & $4(1-4)$ & NS \\
\hline Smoking $(\%)$ & $3(10.3)$ & $4(16)$ & $0(0)$ & NS \\
\hline MAP (range) & $80(72-80)$ & $83(78-99)$ & - & NS \\
\hline MSP (range) & $133(99-160)$ & $122(78-159)$ & - & NS \\
\hline MDP (range) & $68(51-91)$ & $64(48-83)$ & - & NS \\
\hline ICP (range) & $11(2-24)$ & $10(3-20)$ & - & NS \\
\hline TCD values (range) & $157.5(130-350)$ & $154.6(140-244)$ & $<120$ & $0.37^{*}$ \\
\hline Hematocrit (range) & $33(29-34)$ & $33(29-42)$ & - & NS \\
\hline Glucose (range) & $122(88-174)$ & $128(103-173)$ & - & NS \\
\hline GCS (range) & $2(1-4)$ & $2(1-7)$ & - & NS \\
\hline Nimodipine iv (yes/no) & $6 / 23$ & $19 / 6$ & & $<0.001$ \\
\hline HTN & $16 / 13$ & $12 / 13$ & $9 / 11$ & NS \\
\hline Diabetes & $1 / 28$ & $1 / 24$ & $2 / 18$ & NS \\
\hline COPD & $2 / 27$ & $1 / 24$ & $0 / 20$ & NS \\
\hline Renal insufficiency & $1 / 28$ & $1 / 24$ & $0 / 20$ & NS \\
\hline Stroke & $0 / 29$ & $1 / 24$ & $0 / 20$ & NS \\
\hline Alcoholism & $2 / 27$ & $2 / 23$ & $2 / 18$ & NS \\
\hline Atherosclerosis & $2 / 27$ & $1 / 24$ & $1 / 19$ & NS \\
\hline Drug history general & $13 / 16$ & $12 / 13$ & $7 / 13$ & NS \\
\hline Antihypertensive drugs & $7 / 22$ & $8 / 17$ & $3 / 17$ & NS \\
\hline $\mathrm{Ca}^{2+}$ antagonist & $0 / 29$ & $0 / 25$ & $0 / 20$ & NS \\
\hline Anticholesterol drugs & $4 / 25$ & $2 / 23$ & $0 / 20$ & NS \\
\hline Cortisone & $1 / 28$ & $0 / 25$ & $0 / 20$ & NS \\
\hline Antidiabetics & $1 / 28$ & $0 / 25$ & $0 / 20$ & NS \\
\hline Beta blocker & $4 / 25$ & $7 / 18$ & $2 / 18$ & NS \\
\hline Aspirin & $1 / 28$ & $1 / 24$ & $2 / 18$ & NS \\
\hline
\end{tabular}

outcome of patients, the mNIHSS and the mRS scores were assessed at least 3 months after discharge. The modified Fisher grades and the $\mathrm{HH}$ grades are presented in Table 3. This clinical post hoc analysis was regarded as a therapeutic attempt in accordance with the Declarations of Helsinki. The patients themselves or their next of kin (because of the clinical condition of the patient) were informed about the application of molsidomine. Data were collected from electronic and paper medical records. $\mathrm{HH}$ grading was used to assess clinical status because signs of decerebration and signs of brainstem injury are included in the HH scale but not in the World Federation of Neurosurgical Societies (WFNS) grading.

\section{Safety and Treatment Data}

The following parameters were documented in addition to the outcome measures (Tables 1-4): $\mathrm{HH}$ and modified
Fisher grade, age, sex, smoking behavior, epidemiological characteristics, comorbidities (with a score for disease relevance for vascular events), comedication, and events at the onset of CVS: changes of clinical condition or GCS score, hemoglobin, hematocrit, ICP, MAP, systolic and diastolic BP, overall TCD values, standard laboratory parameters (data not shown), and oxygenation parameters (data not shown).

\section{Statistical Analysis}

All variables were analyzed with descriptive and inferential statistical methods. Continuous data were described as means and standard deviations if the variables were normally distributed or as medians, minima, first and third quartiles, and maxima if they were not. Differences of metric variables between 2 groups were analyzed with $\mathrm{t}$-tests if the data were approximately normally distributed 
TABLE 2. Aneurysm distribution in the 3 treatment groups

\begin{tabular}{lccc}
\hline & \multicolumn{3}{c}{ No. } \\
\cline { 2 - 4 } Aneurysm Location & MTG & STG-CVS & STG \\
\hline PICA, VA & 2 & 0 & 3 \\
\hline Pericallosal artery & 0 & 0 & 0 \\
\hline ACoA & 6 & 11 & 5 \\
\hline MCA & 11 & 6 & 10 \\
\hline BA & 3 & 2 & 1 \\
\hline PCOA & 2 & 2 & 1 \\
\hline ICA & 5 & 4 & 0 \\
\hline
\end{tabular}

$\mathrm{ACOA}=$ anterior communicating artery; $\mathrm{PICA}=$ posterior inferior cerebellar artery; $\mathrm{PCOA}=$ posterior communicating artery.

and with Wilcoxon's rank-sum test otherwise. Differences between the 3 groups were analyzed by ANOVA for normally distributed data and by the Kruskal-Wallis test otherwise. Categorical data were described with absolute and relative frequencies. Differences between categorical variables were evaluated with the chi-square test or with Fisher's exact test in the case of expected small cell frequencies. When the overall tests for group effects were significant, 2-group comparisons were performed using the multiple comparison adjustment of Bonferroni. Three subgroup analyses were performed for both the mRS score and the NIHSS score. To adjust for type 1 errors due to multiple subgroup analysis, the Bonferroni approach was used.

All $\mathrm{p}$ values were 2 -sided. For overall tests, $\mathrm{p} \leq 0.05$ was considered significant, and for multiple comparisons and subgroup analyses, Bonferroni-adjusted significance levels were used. All calculations were performed with the statistical analysis software SAS (SAS Institute Inc., version 9.2).

\section{Results}

\section{Patient Characteristics}

No significant differences were detected for any epidemiological parameter (comorbidities or comedications, smoking behavior, sex) among the 3 groups except for age. Patients in the MTG and the STG-CVS were significantly younger than those in the STG-noCVS $(p=0.002$; Table 1). There was no difference in the severity of SAH based on the HH grade or modified Fisher grade (Table 3; Kruskal-Wallis test).

\section{Hemodynamic, Clinical, and Laboratory Findings}

For the MTG and STG-CVS, we determined the hemodynamic and laboratory parameters (data not shown), ICP values, and number of blood transfusions (data not shown), as well as the clinical presentation of CVS, decrease in GCS scores, and length of time of CVS at the estimated day of onset. There were no significant differences between these groups. However, patients in the STG-CVS received significantly more intravenous nimodipine than patients from the MTG. All patients with CVS who were not deeply sedated (GCS score > 7; MTG 19/29; STG-
TABLE 3. Distribution of SAH severity within groups

\begin{tabular}{cccc}
\hline & \multicolumn{3}{c}{ No. } \\
\cline { 2 - 4 } Grade & MTG & STG-CVS & STG-noCVS \\
\hline Fisher & & & \\
\hline 1 & 1 & 0 & 0 \\
\hline 2 & 0 & 4 & 6 \\
\hline 3 & 7 & 5 & 12 \\
\hline 4 & 21 & 16 & 1 \\
\hline HH & & & 1 \\
\hline I & 5 & 4 & 6 \\
\hline II & 2 & 2 & 11 \\
\hline III & 8 & 5 & 1 \\
\hline V & 11 & 13 & \\
\hline
\end{tabular}

There are no significant group differences for Fisher grade and $\mathrm{HH}$ grade.

CVS 18/25) developed progressive clinical worsening (data not shown) and a decrease in the GCS score at the onset of CVS (described as $\triangle \mathrm{GCS}$ points) without differences between the 2 groups $(\mathrm{p}=0.84)$. All coagulation parameters were in the normal range; all patients receiving coil treatment were given aspirin $(100 \mathrm{mg} /$ day $)$ until discharge and for up to 3 months afterwards. Patients who received a stent were additionally treated with clopidogrel (75 mg/day). Relevant mean flow velocity values for anterior circulation in TCD were measured daily and ranged (min-max) from $130 \mathrm{~cm} / \mathrm{sec}$ to $350 \mathrm{~cm} / \mathrm{sec}$ in the MTG and from $130 \mathrm{~cm} / \mathrm{sec}$ to $245 \mathrm{~cm} / \mathrm{sec}$ in the STG-CVS. Average flow velocity values (all vessels) were $157.5 \mathrm{~cm} / \mathrm{sec}$ in the MTG and $154.6 \mathrm{~cm} / \mathrm{sec}$ in the STG-CVS. In the MTG and STG-CVS, CVS remained detectable by TCD for 5 days (median $=5$, lower quartile $[\mathrm{LQ}]=3$, upper quartile $[\mathrm{UQ}]=7$ vs median $=6, \mathrm{LQ}=3$, $\mathrm{UQ}=9$, respectively; $\mathrm{p}=0.13$ ). Despite an increase in the molsidomine dose during the CVS phase, ICP values (data not shown) remained unchanged.

\section{CVS, Infarcts, and Outcome}

The frequency of CVS-related infarcts is presented in Table 5. Four of 29 patients $(13.8 \%)$ in the MTG and 22 of 45 patients $(48.9 \%)$ in the control group developed delayed infarcts ( $\mathrm{p}=0.002$, chi-square test). Out of these 22 patients in the control group with infarcts, 15 patients presented with TCD-proven vasospasm and 7 patients

TABLE 4. Group distribution by patient sex and age

\begin{tabular}{|c|c|c|c|c|c|}
\hline \multirow[b]{2}{*}{ Group } & \multirow[b]{2}{*}{ No. } & \multirow{2}{*}{$\begin{array}{c}\text { Sex } \\
(\mathrm{M} / \mathrm{F})\end{array}$} & \multicolumn{3}{|c|}{ Age (years) } \\
\hline & & & Median & Range & SD \\
\hline MTG & 29 & $8 / 21$ & 49 & $26-77$ & 12.2 \\
\hline STG-CVS & 25 & $10 / 15$ & 52 & $16-76$ & 15.96 \\
\hline STG-noCVS & 20 & $6 / 14$ & $64^{*}$ & $42-86$ & 12.6 \\
\hline
\end{tabular}

* There are no significant differences between the MTG and STG-CVS. Patients in the STG-noCVS were significantly older than patients in the MTG and STG-CVS 
TABLE 5. Vasospasm-related infarcts*

\begin{tabular}{clcc}
\hline Parameter & MTG & STG-CVS & STG-noCVS \\
\hline HH Grade & & & \\
\hline I & 1 & 3 & 1 \\
\hline II & 0 & 1 & 0 \\
\hline III & 1 & 2 & 0 \\
\hline IV & 2 & 8 & 5 \\
\hline V & 0 & 1 & 1 \\
\hline Total no. (\%) & $4(13.8)$ & $15(60)$ & $7(35)$ \\
\hline
\end{tabular}

* Number of vasospasm-related infarcts in relation to HH Grades I-V.

without. Comparing ischemic lesions in the MTG versus the STG-CVS, a significantly lower infarction rate was observed in the MTG (MTG vs STG-CVS, p < 0.0004, chi-square test, Bonferroni 0.0166).

At the 3-month follow-up, assessment of patients in the MTG demonstrated a significantly better clinical outcome than those in the entire STG, as evaluated using the mNIHSS and mRS (mNIHSS, $\mathrm{p}=0.037$, Kruskal-Wallis test; $\mathrm{mRS}, \mathrm{p}=0.0006$ ). The values for the MTG (mNIHSS, median $=0.5, \mathrm{LQ}=0, \mathrm{UQ}=6.5 ; \mathrm{mRS}$, median $=1.0, \mathrm{LQ}=$ $0, \mathrm{UQ}=3.0$ ) can be compared with the values for the STGCVS (mNIHSS, median $=7.5, \mathrm{LQ}=1.0, \mathrm{UQ}=25.5 ; \mathrm{mRS}$, median $=5.0, \mathrm{LQ}=2.0, \mathrm{UQ}=6.0$ ) and the STG-noCVS $(\mathrm{mNIHSS}$, median $=6.0, \mathrm{LQ}=2.0, \mathrm{UQ}=10.0 ; \mathrm{mRS}, \mathrm{me}-$ dian $=4.0, \mathrm{LQ}=2.0, \mathrm{UQ}=5.0$ ). The difference in the $\mathrm{mRS}$ score was significant for both MTG versus STG-CVS ( $p$ $=0.0011)$ and for MTG versus STG ( $p=0.006$, KruskalWallis test, Bonferroni 0.0166) as well as in the entire STG ( $p<0.0006$, Kruskal-Wallis test).

We subdivided all patients into 2 groups: $\mathrm{HH}$ Grades I-II and HH Grades III-V. No significant differences were found in HH Grades I-II between MTG and the STG. However, for HH Grades III-V, a subgroup analysis revealed that in the MTG, the outcome as measured by mNIHSS was significantly better (median $=3, \mathrm{LQ}=0$, UQ $=8$ ) than in the STG-CVS (median $=11.5, \mathrm{LQ}=4.5, \mathrm{UQ}=$ 29.5; $p=0.013)$. The MTG also had a lower average $m R S$ score (median $=2.5 ; \mathrm{LQ}=0, \mathrm{UQ}=4$ ) than the STG-CVS (median $=5.0, \mathrm{LQ}=4, \mathrm{UQ}=6 ; \mathrm{p}=0.0003$, Wilcoxon's 2-sample test, Bonferroni 0.0166).

By the beginning of 2012, 12 patients from the MTG had returned to their jobs as compared with 6 patients in the STG ( $p=0.02)$. Sixty-one of the $74(82 \%)$ patients enrolled in the study had survived the SAH for at least 3 months and $13(17.6 \%)$ patients had died. Nine patients in the STG-CVS died, 3 patients in the STG-noCVS died, and 1 patient in the MTG died. Mortality rate was significantly lower in the MTG than in the STG-CVS ( $\mathrm{p}=$ 0.0034, Fisher's exact test, Bonferroni 0.0166).

\section{Intraarterial Evaluation and Treatment}

CVS detected by arteriography (Fig. 2 upper) reached percentages similar to those of CVS detected by TCD (Fig. 2 lower; $p=0.61$ ). In the STG-CVS, there was a trend towards using a higher number of intraarterial nimodipine applications as a rescue therapy in addition to intravenous nimodipine, but this level was not statistically significant $(\mathrm{p}=0.056)$.

\section{Molsidomine Effects}

Molsidomine did not evoke any serious side effects except for a mild drop in BP values in some patients. No relevant alteration of BP was observed in 17 patients, whereas low-dose noradrenalin administration (maximal $0.2 \mu \mathrm{g} / \mathrm{kg} / \mathrm{min}$ ) was necessary to prevent hypotension in 8 patients. In 2 out of 29 patients with intermittent low output on the first days following SAH or with sepsis and symptomatic hypotension, extended vasopressor treatment was necessary and the molsidomine dosage was kept at a low level (1 mg/hr). In most cases, even with high-dose molsidomine, the MAP was held above $65-70 \mathrm{~mm} \mathrm{Hg}$ using $6 \%$ HES.

\section{Discussion}

Our findings demonstrate a significantly lower frequency of vasospasm-related infarctions and a significantly better clinical outcome in SAH patients treated with molsidomine as compared with patients who received standard nimodipine therapy alone. Surprisingly, we did not observe a significant alteration of blood flow velocities as measured by TCD, which we had expected as a potential side effect of molsidomine on the cerebral conductive vasculature. ${ }^{25,27}$ The beneficial effect of molsidomine treatment on clinical outcome could be explained by its NO-related protective effect on the brain rather than as a therapeutic effect on vasospasm of the conductive vessels. This confirms the findings from the recently published cilostazol trial, in which an endothelial protective effect is attributed to elevating intracellular NO levels through the inhibition of phosphodiesterase 3 by using cilostazol. ${ }^{26}$ Our findings also suggest that molsidomine targets the microvasculature, which may not be directly detectable by TCD or DSA.

Only about one-third of cerebral blood flow (CBF) is controlled by conductive arteries, while two-thirds is controlled by small cerebral vessels distributing blood to the cortex and brain parenchyma. ${ }^{31}$ Vasospasm of the small arteries may have an important impact on clinical outcome. . $^{11,12,18,19,31}$ These small cerebral vessels that contribute to the regional $\mathrm{CBF}$ and autoregulatory vasodilation are strictly dependent on the presence of adequate amounts of NO. Disturbances in the microcirculation associated with SAH are caused by an acute, subacute, and delayed endothelial dysfunction leading to and caused by a loss of NO synthases with a subsequent lack of available NO. This results in the dysfunctional autoregulation of small vessels and triggers a procoagulative state because NO suppresses platelet aggregation, declines leukocyte adhesion, and buffers oxygen-free species., $3,4,6,12,18,19,21,23$ Moreover, subarachnoid blood releases various toxic products by clot lysis, which are potent $\mathrm{NO}$ antagonists that scavenge NO and degrade or inhibit NO synthases. This "NO sink effect" increases oxidative stress, myosin phosphorylation, apoptosis and necrosis of neurons, formation of microthrombi, and permanent remodeling of the cerebral wall architecture..$^{19,22,28-30,32}$ Each of these mechanisms alone or 


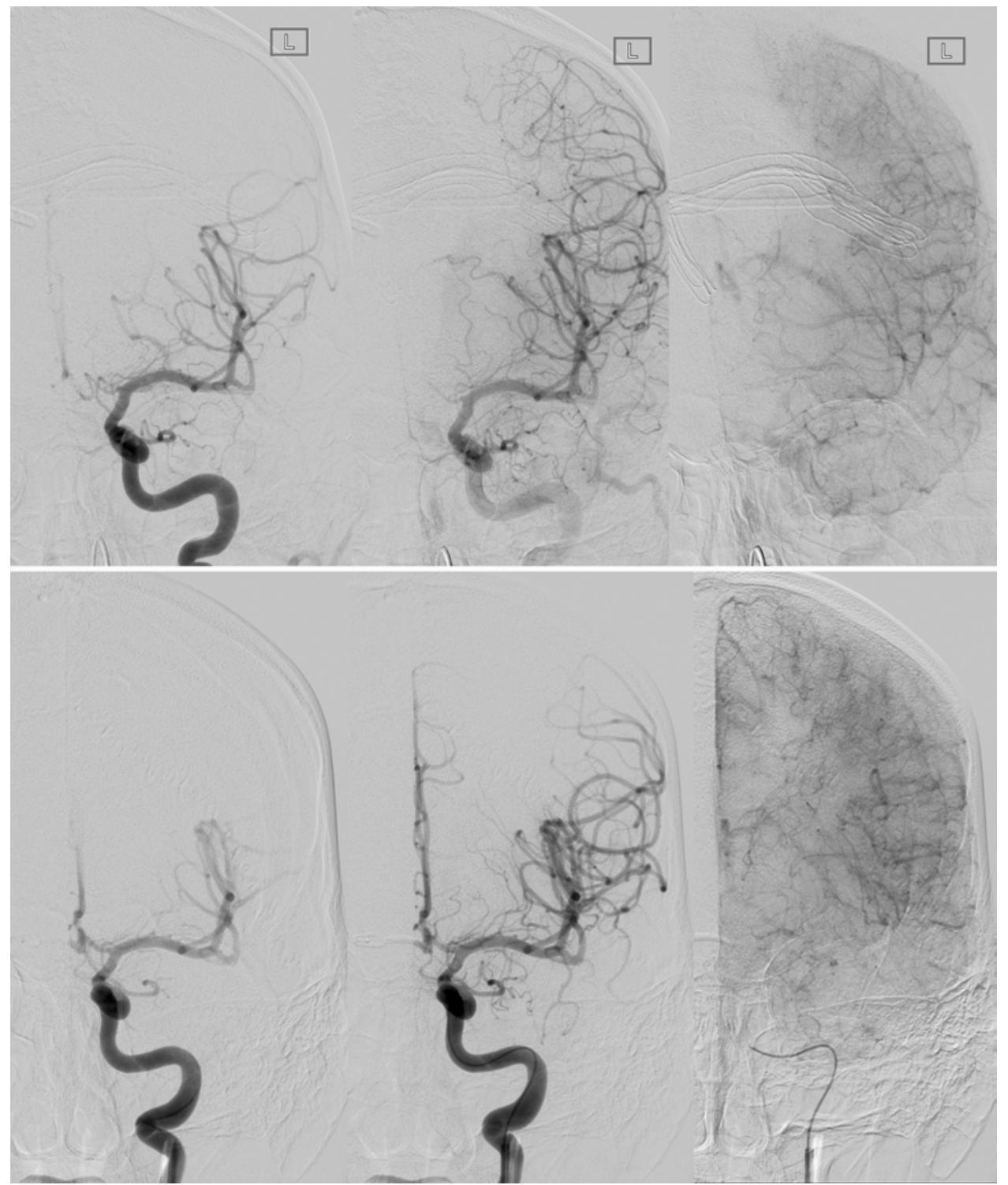

FIG. 2. Images obtained in a 27-year-old male with an aneurysm of the anterior communicating artery. Upper: Clip occlusion and initial diagnostic DSA of the left ICA showed massive vasospasm with reduced vessel diameter of the $A_{1}$ and $M_{2-3}$ branches and a disturbed contrast outflow. Lower: DSA after administration of the maximum molsidomine dose for 2 days (DSA done on Day 2) showing normalized vessel diameters on the circle of Willis and a normalized outflow pattern in the parenchymal phase.

in combination could be responsible for impaired microcirculation and the occurrence of DINDs, ${ }^{4,18,19}$ and each of them can theoretically be counteracted by an increase of NO availability.

The brain-protective action of NO after SAH is not limited to improving CBF. In the brain, NO also plays a critical role in preconditioning against cerebral ischemia, and it inhibits neuronal apoptosis in the ischemic penumbra. ${ }^{8}$ Furthermore, in ischemia, NO improves the reuptake of excitatory amino acids and inhibits the immunological response and activation of microglia. ${ }^{8}$ Also, a lack of $\mathrm{NO}$ triggers the onset of cortical spreading depression and related ischemia. ${ }^{8}$ Therefore, $\mathrm{NO}$ administration limits damage to the brain by any of these mechanisms including cortical spreading ischemias. ${ }^{8,10}$

\section{Conclusions}

Our preliminary results show that molsidomine is a promising therapeutic agent for the treatment of DINDs after SAH. The findings of this study warrant a randomized clinical trial using molsidomine for the treatment of patients with SAH.

\section{Acknowledgments}

We thank Andre Kemmling (Department of Neuroradiology, University Hospital Luebeck), Christoph Terborg (Department of Neurology, Asklepios Hospital St. Georg), Peter Wohlmuth (Asklepios Pro Research, Hamburg), Thomas Niederstadt (Department of Radiology, University Hospital Münster), and Volkert Thomas (Department of Anesthesiology, University Hospital Münster) for their generous support in performing this research. 


\section{References}

1. Al-Khindi T, Macdonald RL, Schweizer TA: Cognitive and functional outcome after aneurysmal subarachnoid hemorrhage. Stroke 41:e519-e536, 2010

2. Allen GS, Ahn HS, Preziosi TJ, Battye R, Boone SC, Boone $\mathrm{SC}$, et al: Cerebral arterial spasm-a controlled trial of nimodipine in patients with subarachnoid hemorrhage. N Engl J Med 308:619-624, 1983

3. Bassenge E, Pohl U, Busse R: Generation and transmission of vasoactive and antiaggregatory signals by the endothelium. Adv Second Messenger Phosphoprotein Res 24:434-440, 1990

4. Bassenge E, Schneider HT, Daiber A: [Oxidative stress and cardiovascular diseases.] Dtsch Med Wochenschr 130:2904-2909, 2005 (Ger)

5. Bevan JA, Bevan RD, Walters CL, Wellman T: Functional changes in human pial arteries (300 to 900 micrometer ID) within 48 hours of aneurysmal subarachnoid hemorrhage. Stroke 29:2575-2579, 1998

6. Busse R, Trogisch G, Bassenge E: The role of endothelium in the control of vascular tone. Basic Res Cardiol 80:475-490, 1985

7. Casthely PA, Cottrell JE, Patel KP, Marlin A, Turndorf H: Cerebrospinal fluid cyanide after nitroprusside infusion in man. Can Anaesth Soc J 28:228-231, 1981

8. Dirnagl U, Becker K, Meisel A: Preconditioning and tolerance against cerebral ischaemia: from experimental strategies to clinical use. Lancet Neurol 8:398-412, 2009

9. Dorsch NW: Therapeutic approaches to vasospasm in subarachnoid hemorrhage. Curr Opin Crit Care 8:128-133, 2002

10. Dreier JP, Ebert N, Priller J, Megow D, Lindauer U, Klee R, et al: Products of hemolysis in the subarachnoid space inducing spreading ischemia in the cortex and focal necrosis in rats: a model for delayed ischemic neurological deficits after subarachnoid hemorrhage? J Neurosurg 93:658-666, 2000

11. Faraci FM: Role of endothelium-derived relaxing factor in cerebral circulation: large arteries vs. microcirculation. Am J Physiol 261:H1038-H1042, 1991

12. Faraci FM, Brian JE Jr: Nitric oxide and the cerebral circulation. Stroke 25:692-703, 1994

13. Frontera JA, Fernandez A, Schmidt JM, Claassen J, Wartenberg KE, Badjatia N, et al: Defining vasospasm after subarachnoid hemorrhage: what is the most clinically relevant definition? Stroke 40:1963-1968, 2009

14. Komotar RJ, Schmidt JM, Starke RM, Claassen J, Wartenberg KE, Lee K, et al: Resuscitation and critical care of poorgrade subarachnoid hemorrhage. Neurosurgery 64:397-411, 2009

15. Kramer A, Fletcher J: Do endothelin-receptor antagonists prevent delayed neurological deficits and poor outcomes after aneurysmal subarachnoid hemorrhage?: a meta-analysis. Stroke 40:3403-3406, 2009

16. Loch Macdonald R: Management of cerebral vasospasm. Neurosurg Rev 29:179-193, 2006

17. Nolan CP, Macdonald RL: Can angiographic vasospasm be used as a surrogate marker in evaluating therapeutic interventions for cerebral vasospasm? Neurosurg Focus 21(3):E1, 2006

18. Ohkuma H, Manabe H, Tanaka M, Suzuki S: Impact of cerebral microcirculatory changes on cerebral blood flow during cerebral vasospasm after aneurysmal subarachnoid hemorrhage. Stroke 31:1621-1627, 2000

19. Pluta RM: Delayed cerebral vasospasm and nitric oxide: review, new hypothesis, and proposed treatment. Pharmacol Ther 105:23-56, 2005

20. Pluta RM, Dejam A, Grimes G, Gladwin MT, Oldfield EH:
Nitrite infusions to prevent delayed cerebral vasospasm in a primate model of subarachnoid hemorrhage. JAMA 293:1477-1484, 2005

21. Pluta RM, Hansen-Schwartz J, Dreier J, Vajkoczy P, Macdonald RL, Nishizawa S, et al: Cerebral vasospasm following subarachnoid hemorrhage: time for a new world of thought. Neurol Res 31:151-158, 2009

22. Pluta RM, Rak R, Wink DA, Woodward JJ, Khaldi A, Oldfield $\mathrm{EH}$, et al: Effects of nitric oxide on reactive oxygen species production and infarction size after brain reperfusion injury. Neurosurgery 48:884-893, 2001

23. Pluta RM, Thompson BG, Afshar JK, Boock RJ, Iuliano B, Oldfield EH: Nitric oxide and vasospasm. Acta Neurochir Suppl 77:67-72, 2001

24. Rinkel GJ, Algra A: Long-term outcomes of patients with aneurysmal subarachnoid haemorrhage. Lancet Neurol 10:349-356, 2011

25. Rosenkranz B, Winkelmann BR, Parnham MJ: Clinical pharmacokinetics of molsidomine. Clin Pharmacokinet 30:372-384, 1996

26. Senbokuya N, Kinouchi H, Kanemaru K, Ohashi Y, Fukamachi A, Yagi S, et al: Effects of cilostazol on cerebral vasospasm after aneurysmal subarachnoid hemorrhage: a multicenter prospective, randomized, open-label blinded end point trial. J Neurosurg 118:121-130

27. Serruys PW, Deckers JW, Luijten HE, Reiber JH, Tijssen JG, Chadha $\mathrm{D}$, et al: Long-acting coronary vasodilatory action of the molsidomine metabolite Sin 1: a quantitative angiographic study. Eur Heart J 8:263-270, 1987

28. Smith RR, Clower BR, Grotendorst GM, Yabuno N, Cruse JM: Arterial wall changes in early human vasospasm. Neurosurgery 16:171-176, 1985

29. Sobey CG, Faraci FM: Subarachnoid haemorrhage: what happens to the cerebral arteries? Clin Exp Pharmacol Physiol 25:867-876, 1998

30. Stein SC, Browne KD, Chen XH, Smith DH, Graham DI: Thromboembolism and delayed cerebral ischemia after subarachnoid hemorrhage: an autopsy study. Neurosurgery 59:781-788, 2006

31. Ursino M: Regulation of the circulation of the brain, in Bevan RD, Bevan JA (eds): The Human Brain Circulation: Functional Changes in Disease. New York: Humana Press, 1994, pp pp. 291-318

32. Vergouwen MD, Vermeulen M, Coert BA, Stroes ES, Roos YB: Microthrombosis after aneurysmal subarachnoid hemorrhage: an additional explanation for delayed cerebral ischemia. J Cereb Blood Flow Metab 28:1761-1770, 2008

33. Vergouwen MD, Vermeulen M, van Gijn J, Rinkel GJ, Wijdicks EF, Muizelaar JP, et al: Definition of delayed cerebral ischemia after aneurysmal subarachnoid hemorrhage as an outcome event in clinical trials and observational studies: proposal of a multidisciplinary research group. Stroke 41:2391-2395, 2010

\section{Author Contributions}

Conception and design: Hesselmann. Analysis and interpretation of data: Hesselmann. Drafting the article: Hesselmann, Ehlert, Schmidt, Wölfer, Jacobs, Brüning, Stummer, Pluta. Critically revising the article: all authors. Reviewed submitted version of manuscript: all authors. Approved the final version of the manuscript on behalf of all authors: Hesselmann.

\section{Correspondence}

Volker Hesselmann, Department of Radiology and Neuroradiology, Asklepios Clinic Hamburg, North, Tangstedter Landstrasse 400, Hamburg, Germany. email: v.hesselmann@asklepios.com. 